
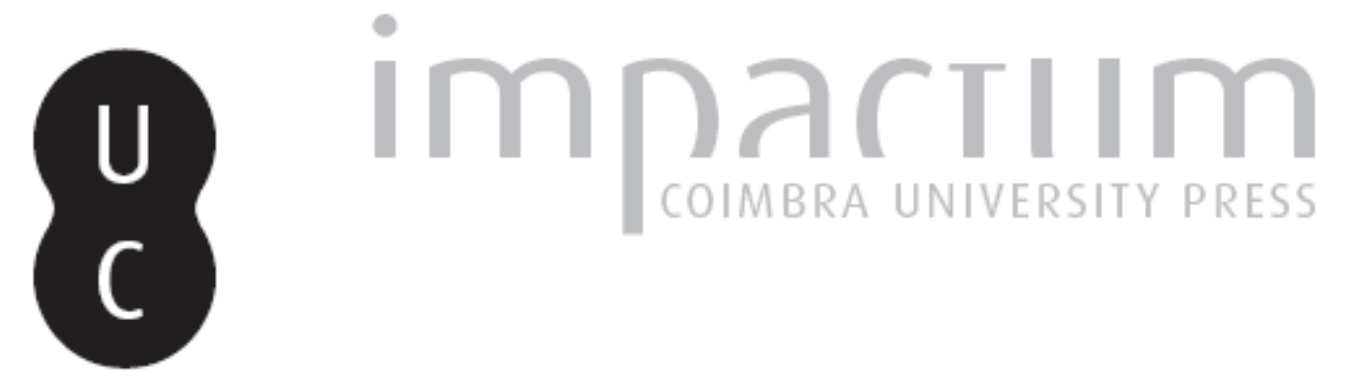

\title{
Prática da arquitectura e disposição antropológica
}

Autor(es): Providência, Paulo

Publicado por: Editorial do Departamento de Arquitetura

URL persistente:

URI:http://hdl.handle.net/10316.2/37399

DOI:

DOI:http://dx.doi.org/10.14195/1647-8681_2_7

Accessed : $\quad$ 26-Apr-2023 13:45:51

A navegação consulta e descarregamento dos títulos inseridos nas Bibliotecas Digitais UC Digitalis, UC Pombalina e UC Impactum, pressupõem a aceitação plena e sem reservas dos Termos e Condições de Uso destas Bibliotecas Digitais, disponíveis em https://digitalis.uc.pt/pt-pt/termos.

Conforme exposto nos referidos Termos e Condições de Uso, o descarregamento de títulos de acesso restrito requer uma licença válida de autorização devendo o utilizador aceder ao(s) documento(s) a partir de um endereço de IP da instituição detentora da supramencionada licença.

Ao utilizador é apenas permitido o descarregamento para uso pessoal, pelo que o emprego do(s) título(s) descarregado(s) para outro fim, designadamente comercial, carece de autorização do respetivo autor ou editor da obra.

Na medida em que todas as obras da UC Digitalis se encontram protegidas pelo Código do Direito de Autor e Direitos Conexos e demais legislação aplicável, toda a cópia, parcial ou total, deste documento, nos casos em que é legalmente admitida, deverá conter ou fazer-se acompanhar por este aviso.

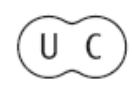



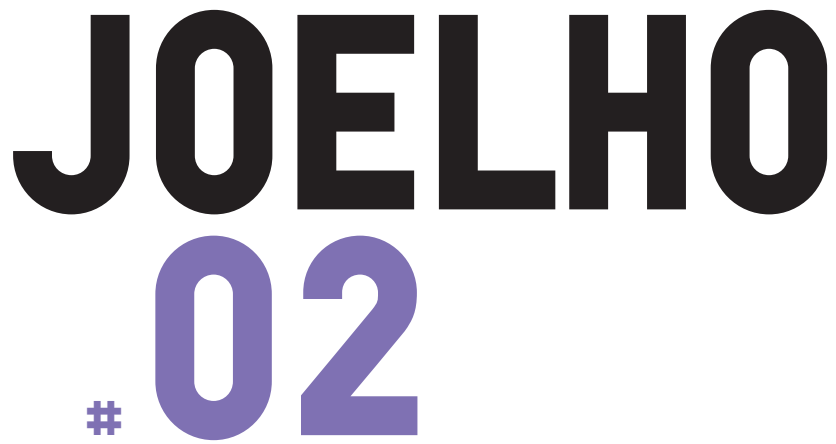

INTERSECCÓES:

ANTROPOLOGIA

E ARQUITECTURA

Coordenação:

Paulo Providência

Sandra Xavier

Luís Quintais

Comunicações:

Georges Teyssot

James Holston

João Leal

Sergio Fernandez

Comentários:

Jorge Figueira

José António Bandeirinha

Luís Quintais

Paulo Providência

Sandra Xavier 


\section{Paulo Providência}

\section{Prática da Arquitectura e Disposição Antropológica}

Positividade, disposição e dispositivo "A antropologia constitui talvez a filosofia fundamental que tem orientado e conduzido o pensamento filosófico desde Kant até hoje. Esta disposição é essencial, pois faz parte da nossa história;(...) A todos os que pretendem ainda falar do homem, do seu reino ou da sua libertação, (...) a todos os que não se propõem formalizar sem antropologizar, que não pretendem mitologizar sem desmistificar, que não querem pensar sem pensar logo que é o homem que pensa, a todas essas formas de reflexão canhestras e torcidas, não se pode senão opor um riso filosófico - quer dizer, em certa medida, silencioso." Assim, Foucault (2005) dirige a sua crítica à antropologia tal como se inicia no final do século XVIII, a ciência que se debruça sobre o homem, ou que procura definir o que é humano no homem (Was ist der Mensch?), o ser do homem (Menschsein), recusando qualquer teoria ou teologia da libertação; por outro lado, essa "antropologia" surge como disposição essencial do pensamento contemporâneo, ou, pelo menos, o que percorre o século XIX até hoje; e aqui disposição surge associada às positividades que percorrem Les Mots et les Choses; o que são, portanto, essas "disposições", essas "positividades" que condicionam o homem no pensar? Que disposição é essa instaurada com o aparecimento da Antropologia? É a esta questão que Agamben responde.

Agamben (2007) chama a atenção para a concatenação que se estabelece entre positividade e disposição ou dispositivo. Partindo da apropriação de positividade que vinha de Hegel através de Jean Hyppolite ("o elemento histórico com o seu peso de regras, ritos e instituições que são impostas ao indivíduo por um poder exterior, que são como que interiorizados pelo sistema de crenças e sentimentos") Foucault propõe-se inquirir "sobre os modos concretos pelos quais as positividades (ou os dispositivos) agem no interior das relações, nos mecanismos e jogos de poder." Claro que em Agamben, leitor assíduo e persistente de Walter Benjamin, converge uma reflexão sobre a natureza religiosa do político. E procurando a origem etimológica de dispositivo no termo latino dispositio, Agamben remonta o dispositivo de Foucault a uma herança teológica: "a fractura que separa e reúne em Deus o ser e a praxis, a natureza (ou essência) e a operação pela qual Ele administra e governa o mundo das criaturas. $\bigcirc$ termo dispositivo nomeia aquilo que, e através do qual, se realiza uma pura actividade 
de governação sem o menor fundamento no ser. É por isso que os dispositivos devem sempre implicar um processo de subjectivação. Eles produzem sempre o seu sujeito." Em Agamben, surge assim um momento teológico do dispositivo, que, curiosamente, se socorre do pensamento antropológico para se fundar (Durkheim e o rito; o profano e o sagrado, etc.). Talvez por isso Teyssot procura uma fundamentação da "disposição antropológica" de van Eyck nas leituras de Martin Buber, confirmando a origem teológica da disposição tal como apresentada por Agamben, e procurando com isso afirmar que qualquer promessa de redenção (ou refundação) de uma prática arquitectónica cumpre a mesma economia (ou oikonómia) salvifica, o que quer dizer a mesma dispositio. E isto porque para Teyssot uma das tarefas da crítica de arquitectura será a demonstração das disposições (no sentido de Agamben) que condicionam a arquitectura no seu pensar; mas não incorrerá também numa desmistificação do discurso de van Eyck (pelo menos aparente), ou através da desmontagem das apropriações arquitectónica do discurso antropológico, remetido para uma constelação de sub-entendidos ou mal-entendidos, a uma "revelação da verdade" que a todos tinha escapado?

\section{O projecto de van Eyck}

Talvez o tom incómodo do texto de Teyssot tenha a ver com uma certa hagiografia recente promovida pela Faculdade de Arquitectura da TU de Delft; não me refiro apenas à monografia editada por Vincent Ligtelijn (Aldo van Eyck Works, Birkhauser, 1999), ou à magnifica edição da obra escrita de van Eyck (Aldo van Eyck Writings, ed. por Vincent Ligtelijn e Francis Stauben, SUN, 2008), mas também a Team 10, 195381 - in search of a Utopian of the present, editado por Max Rissalada e Dirk van den Heuvel, NAI Publishers, 2006, que aliás acompanhava a exposição que teve lugar na galeria NAI em Roterdão, ou ainda ao Congresso que no mês de Janeiro desse ano de 2006 teve lugar na Faculty of Architecture da TU Delft, Team 10 - Keeping the Language of Modern Architecture Alive, organizado por Max Rissalada, e editado como actas em 2007 (completando a edição de um Colóquio realizado em 2003 sob o título Team 10 - Between Modernity and the Everyday). Esse tom um pouco áspero é consistente com a participação de Teyssot no colóquio de 2006; e decorre da crítica a uma certa nostalgia de um momento em que a arquitectura teria tido um papel diferente no desenho do espaço público - a ideia de que os arquitectos choram lágrimas de crocodilo pela perda da praça ou àgora, como espaço de reunião e identidade. Trata-se da crítica ao ressurgir nostálgico de um certo empenho social da arquitectura, de natureza puritano e normativo, e que no final terá servido apenas para a afirmação internacional dessa geração.

Na sua comunicação ao Congresso de 2006 da TU Delft Teyssot insiste em desvincular Michel Foucault do estruturalismo, classificação equivoca e contestada; no texto que agora apresenta segue uma via 
idêntica ao aprofundar o equívoco semântico entre super-estructura e estruturalismo; esse equívoco, que perpassa o texto de Arnulf Lüchinger de 1981, é de certa forma subjacente à organização do congresso que apresentava duas grandes secções: uma dedicada à mitopoiesis organizada por Dirk van den Heuvel, e outra à superestructura/estruturalismo organizada por Tom Avermaete; como duas faces da mesma moeda, associava-se a recuperação poética da cultura primitiva, original, arcaica, ou infantil e característica do Homem universal a uma certa identificação da norma, do arquétipo, ou do inconsciente colectivo, como traço regular ou regulador de uma arquitectura mais enraizada, pertinente, ou correspondendo às necessidade humanas. Um texto fundamental nesse congresso é o de Karin Jaschke, que inserido na secção da mitopoiesis faz a historiografia do encontro de van Eyck com os Dogon, texto aliás amplamente referido por Teyssot. Na secção dedicada ao estruturalismo, destaca-se a comunicação de Irénée Scalbert com o título "From anthropology to structuralism": "a crença na necessidade de identificação entre formas de vida e formas arquitectónicas persistiu (...) ○ mais formal poderia também ser o mais social. Pelo menos é o que parece ser a conclusão sugerida pelo estruturalismo nesse tempo." No mesmo sentido, Scalbert aponta que a preocupação com o papel simbólico da arquitectura, baseado na correspondência entre arquitectura e sociedade, é algo completamente estranho ao Estruturalismo (a Antropologia Estrutural de Lévi-Strauss, e mais especificamente o texto fundador de 1949, Les Structures élémentaires da la parenté). No mesmo sentido, o sociólogo Jean-Louis Violeau (2006) havia chamado a atenção para a ambígua relação entre estruturalismo no pensamento filosófico francês e o Team 10, no texto publicado no catálogo da exposição do NAI (Team 10, 1953-81 - in search of a Utopian of the present); mas para Violeau, professor na Escola de arquitectura Paris-Malaquais, tratava-se também de registar a nefasta influência de Henri Lefebvre nas escolas de arquitectura francesas a partir de meados dos anos sessenta, em parte decorrente da substituição dos estiradores de projecto pelo livros de sociologia aconselhada por Candilis na sua tentativa de reforma das Beaux-Arts de Paris, e que também Teyssot, no debate sequente à conferência, refere.

O projecto de van Eyck é construído partindo dos processos de apropriação do espaço urbano através da construção de um conjunto significativo de parques infantis; esse exercício, que se inicia no pósguerra em 1947 prolonga-se até 1978; a aproximação à infância, a que não será estranha a colaboração e montagem de exposições do grupo Cobra (Amesterdão 1949 e Liége 1951), a obra plástica de Karel Appel, um certo elogio de uma aproximação à experiência directa que vê na infância um estado original do lúdico e das suas interpretações no espaço urbano (ver, por exemplo, a comunicação de Dirk van den Heuvel "Team 10 riddles - a few notes on mythopioesis, discourse and epistemology", in Team 10 - Keeping the language of modern 
architecture alive), ou ainda uma aproximação à obra de Constant, ou às psico-geografias dos situacionistas, colocam-nos nos aspectos mais produtivos dessa geração; a obra posterior de van Eyck tal como o lar para órfãos, de 1955-1960, é possibilidade de testagem das suas teorias sobre o umbral, sobre uma certa percepção diagonal do espaço (a janela de canto), sobre a inserção de espelhos nos elementos de betão e outros motivos que, tal como na Alice de Lewis Carrol, nos transportam para um mundo às avessas, ou permitem que esse outro mundo aflore, momentaneamente, no nosso de adultos, desencantados com as obrigações quotidianas; por fim, uma obra particularmente significativa é a casa para as mães solteiras, Hubertus House 1973-1981 em Amesterdão, que retoma e prolonga essas experiências anteriores, e que corresponde a uma fase de maturidade de van Eyck. Mas tudo isso já desapareceu; o lar de órfãos já não é um lar de órfãos, e as mães solteiras já não necessitam de um abrigo estatal promovido por um estado providência; vivem em pequenos apartamentos arrendados, como qualquer outro habitante daquelas terras. Pelo contrário, hoje a sociedade holandesa retomou uma política profundamente liberal consistente com a natureza religiosa do protestantismo, que vê no lucro uma desmultiplicação legítima dos dons concedidos por Deus, e cuja filosofia é o empirismo na melhor tradição Lockeana.

\section{Cultura e nova barbárie}

Mas o que o texto de Teyssot questiona, como pano de fundo e de forma bem mais radical, é precisamente a possibilidade de uma fundamentação humanista para a cultura, e mais especificamente para a cultura arquitectónica; a crítica a essa fundamentação, que procurava recuperar a retórica como dispositivo comunicante, com a acentuação da metáfora, alinha com a resposta à carta sobre o humanismo de Martin Heidegger por Peter Sloterdijk. Para Sloterdijk, “poderíamos reduzir o fantasma comunitário que subjaz a todo o humanismo ao modelo de uma sociedade literária, sociedade em que os participantes descobrem por meio de leituras canónicas o seu comum amor por remetentes inspirados. No cerne do humanismo entendido deste modo descobrimos uma fantasia de seita ou clube, o sonho de fatal solidariedade daqueles que foram eleitos para poderem ler."

Posteriormente Sloterdijk na sua trilogia Sphären refere a espuma como modelo e metáfora da construção e sociedade contemporânea; mas a visão de um homem naturalmente comprimido numa "comunidade" que não deseja, numa relação de "vizinhança" forçada, ou um estado de "excessiva comunicação", levarão a levantar muros, a criar isolamentos, ou a defender-se do excesso de transparência imposta pela modernidade, tal como refere na sua comunicação na GSD de Harvard em 2009: "That would describe a dimension of human coexistence that recognizes that people also have an infinite need for non-communication. Modernity's dictatorial traits all stem from an 
excessively communicative anthropology: For all too long, the dogmatic notion of an excessively communicative image of man was naively adopted. By means of the image of foam you can show that the small forms protect us against fusion with the mass and the corresponding hypersociologies."

Já Walter Benjamin no seu tempo fazia o elogio de uma nova barbárie, de uma barbárie positiva; libertando-se da tradição, a modernidade apela a não deixar vestígios: "Pobreza de experiência: a expressão não significa que as pessoas sintam a nostalgia de uma nova experiência. Não, o que elas anseiam é libertar-se das experiências, anseiam por um mundo em que possam afirmar de forma tão pura e clara a sua pobreza, a exterior e também a interior, que daí nasça alguma coisa que se veja. E também não são sempre ignorantes e inexperientes. Muitas vezes é o contrário que se verifica: tiveram de 'engolir' tudo isso, a 'cultura' e 'o Homem', e ficaram saturadas e cansadas. (...) Nas suas construções, nos seus quadros, nas suas narrativas, a humanidade prepara-se para, se necessário for, sobreviver à cultura. E o que é mais importante: faz isso a rir. Talvez esse riso soe aqui e ali bárbaro. Seja. Desde que cada indivíduo de vez em quando ceda um pouco de humanidade àquelas massas que um dia lha devolverão com juros acrescidos."

\section{Referências bibliográficas}

Agamben, Giorgio, 2007, Qu'est-ce qu'un dispositif?, Paris, Rivages poche / Petite Bibliothèque.

Benjamin, Walter, 2010, "Experiência e indigência" in O Anjo da História, Lisboa, Assírio \& Alvim.

Defert, Daniel, 2007, "Présentation", in: Kant \& Foucault, Athropologia du point de vue pragmatique. Introduction à l'Anthropologie, Paris, Vrin.

Foucault, Michel, 2005, As palavras e as coisas - uma arqueologia das ciências humanas, Lisboa, Edições 70.

Lüchinger, Arnulf, 1981, Strukturalismus in Architektur und Städtebau, Stuttgart, Karl Krämer Verlag.
Scalbert, Irénée, 2007, "From Anthropology to Structuralism", in Team 10 Keeping the Modern Langauge Alive, Faculty of Architecture TU Delft.

一

Sloterdijk, Peter, 2007, Regras para o parque humano, Coimbra, Angelus Novus.

Sloterdijk, Peter, 2009, Spheres Theory: Talking to Myself about the Poetics of Space by Peter Sloterdijk (Harvard University Graduate School of Design, February 17, 2009).

Violeau, Jean-Louis, 2006, "Team 10 and structuralism: analogies and discrepancies", in Team 10, 1853-81: in search of a utopia of the present, Roderdão, NAI Publishers. 